\title{
Energy-Efficient Ammonia Production from Air and Water Using Electrocatalysts with Limited Faradaic Efficiency
}

Cite This: ACS Energy Lett. 2020, 5, 1124-1127

Read Online

ACCESS | L Wll Metrics \& More | 回 Article Recommendations | st Supporting Information

A mmonia is an industrial large-volume chemical. It is used in fertilizers and many chemical products and materials, and it pops up as a candidate green energy vector. Today, the industrial production of ammonia is dominated by the Haber-Bosch process departing from natural gas or other fossil fuel. This process is responsible for about $1.6 \%$ of the global $\mathrm{CO}_{2}$ emissions. Electrochemical ammonia production from water and nitrogen gas using renewable electricity is a potential solution to reduce the $\mathrm{CO}_{2}$ footprint of ammonia production. Electrocatalysts with steadily increasing Faradaic efficiency are being reported, but there seems to be a trade-off between ammonia selectivity and catalytic activity. Hydrogen gas is the main byproduct. Here we show low ammonia selectivity of electrocatalysts not to be an obstacle to energy-efficient ammonia production. The SECAM process (Solar ElectroChemical AMmonia synthesis) integrates nitrogen gas production from air, electrocatalytic ammonia synthesis, reaction product separation, and hydrogen recycling with an overall energy efficiency similar to that of the HaberBosch process. The electrochemical ammonia synthesis process can be powered with photovoltaics and take advantage of the day-night cycle for converting the excess hydrogen byproduct produced during the day to make additional ammonia at night. The process can be operated using electrocatalysts with Faradaic efficiencies of ammonia synthesis as low as $10 \%$. The activity of electrocatalysts is the critical property to be improved for energy-efficient production of green ammonia.

The Haber-Bosch process for ammonia production is one of the oldest industrial catalytic processes. ${ }^{1}$ The first ammonia plant went on stream in $1913 .^{2}$ In the Haber-Bosch process, $\mathrm{N}_{2}$ gas is reduced to $\mathrm{NH}_{3}$ using $\mathrm{H}_{2}$ gas (eq 1):

$$
\mathrm{N}_{2}+3 \mathrm{H}_{2} \rightarrow 2 \mathrm{NH}_{3} \quad E_{0}=0.057 \mathrm{~V}
$$

Elevated temperatures are needed to activate the iron-based catalyst. The reaction kinetics are peculiar in the sense that the chemisorption of nitrogen gas molecules on the catalyst surface limits the reaction rate. ${ }^{3,4}$ The $\mathrm{H}_{2}$ for the Haber-Bosch process is typically produced by methane steam reforming. $\mathrm{CO}_{2}$ emission of the Haber-Bosch process amounts to up to 1.9 ton per ton of ammonia produced. ${ }^{5}$ In 2017, ammonia production worldwide was responsible for ca. $420 \mathrm{Mt}$ of $\mathrm{CO}_{2}{ }^{6}$
The use of water and electricity instead of hydrogen out of methane is an alternative pathway for ammonia synthesis (eq 2).

$$
\mathrm{N}_{2}+3 \mathrm{H}_{2} \mathrm{O} \rightarrow 2 \mathrm{NH}_{3}+\frac{3}{2} \mathrm{O}_{2} \quad E_{0}=-1.164 \mathrm{~V}
$$

Different types of electrocatalysts performing this reaction have been reported, but they exhibit two shortcomings: low activity and low ammonia selectivity. Currently, the highest reported Faradaic efficiencies of electrochemical ammonia synthesis from water and air are in the range of $60 \% .^{6-8}$ One exception, which uses a fundamentally different process with $\mathrm{Li}$-cycling, achieves a Faradaic efficiency of $88.5 \%$ at a temperature of 450 ${ }^{\circ} \mathrm{C}$. ${ }^{9}$ Common electrochemical ammonia synthesis has hydrogen gas as the main byproduct, consuming a significant part of the invested electric energy. The SECAM process presented here uses this hydrogen gas for two purposes: (i) reaction with oxygen out of the air to prepare nitrogen gas and water to be fed to the ammonia synthesis reactor and (ii) performing electrocatalytic ammonia synthesis using $\mathrm{H}_{2}$. The SECAM process has two modes of operation: energy-intensive production of ammonia out of nitrogen gas and water according to eq 1 (mode A, Figure 1) and an energy-extensive production of ammonia out of an $\mathrm{N}_{2} / \mathrm{H}_{2}$ gas mixture according to eq 2 (mode B, Figure 1 ).

In mode A (Figure 2A), air is used as a source of nitrogen. To make air suitable for ammonia production, $\mathrm{O}_{2}$ is removed by reaction with $\mathrm{H}_{2}$. This can be done in a fuel cell, generating electricity, or in a burner, generating heat to recover the energy. Next, the obtained gas containing already some water from the reaction of $\mathrm{O}_{2}$ with $\mathrm{H}_{2}$, is sent through a humidifier where additional water vapor is added. After these two steps, the hydrated nitrogen gas is fed to the electrochemical cell, where ammonia is formed on the cathode. The hydrogen evolution reaction (HER) competes with ammonia synthesis. When mode $\mathrm{A}$ is run such as to produce exactly the amount of

Received: February 27, 2020

Accepted: March 5, 2020

Published: March 17, 2020

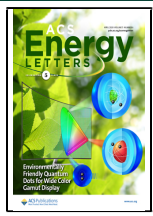




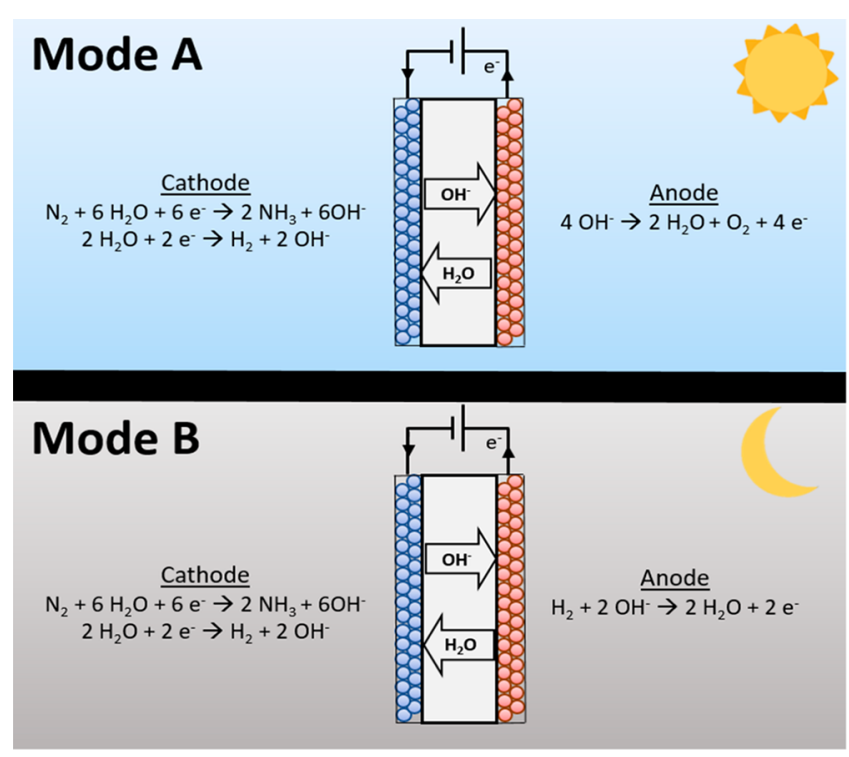

Figure 1. Overview of the half reactions occurring in the electrochemical cell, for mode A and mode B.

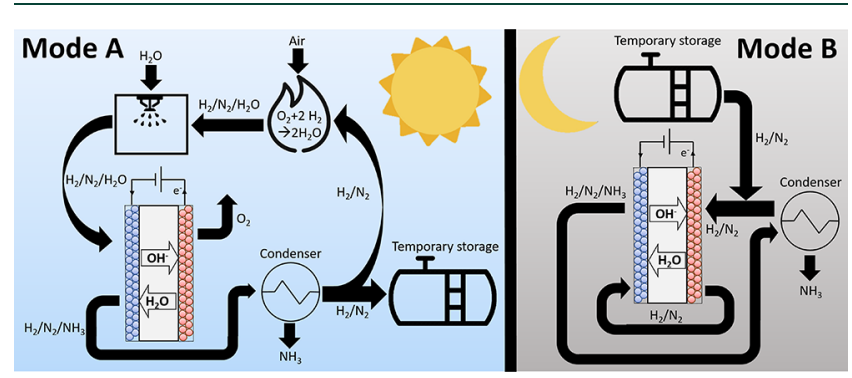

Figure 2. SECAM process for electrochemical ammonia production. (A) Energy-intensive operation mode of the electrochemical reactor, producing ammonia from water and air. (B) Energyextensive operation mode of the electrochemical reactor, producing ammonia from an $\mathrm{N}_{2} / \mathrm{H}_{2}$ gas mixture.

hydrogen needed to eliminate the $\mathrm{O}_{2}$ from the intake air, the electrocatalyst should have a Faradaic efficiency for ammonia production of $85 \%$. State-of-the-art electrocatalysts have lower Faradaic efficiencies, ${ }^{10}$ and excess $\mathrm{H}_{2}$ gas is produced. The resulting outlet gas of the cathode compartment is composed of $\mathrm{NH}_{3}, \mathrm{H}_{2}$, and unreacted $\mathrm{N}_{2} . \mathrm{NH}_{3}$ is condensed out of the gas stream, resulting in a residual stream of $\mathrm{N}_{2}$ and $\mathrm{H}_{2}$. Part of this stream serves the $\mathrm{O}_{2}$ removal out of inlet air; part is stored in a tank as feed for mode $\mathrm{B}$. Water is the source of $\mathrm{H}$ atoms and air is the source of $\mathrm{N}$ atoms. The molar ratio of the excess $\mathrm{N}_{2} / \mathrm{H}_{2}$, produced in mode $\mathrm{A}$, is fixed at $1 / 3$ by tuning the air and water intake of the process.

In mode $\mathrm{B}$ (Figure $2 \mathrm{~B}$ ), the $\mathrm{H}_{2} / \mathrm{N}_{2}$ gas mixture from the storage vessel is sent to the anode of the electrochemical cell, where the hydrogen oxidation reaction (HOR) takes place. Next, the remaining gas is sent to the cathode, where ammonia and hydrogen gas are formed. In mode $\mathrm{B}$ ammonia is produced until all $\mathrm{N}_{2}$ and $\mathrm{H}_{2}$ gas is converted by recycling.

Modes A and B make use of the same electrochemical cell. Ammonia production in mode B consumes less than $20 \%$ of the electric power required for mode $A$.

Operation of SECAM according to modes $A$ and $B$ is dependent on the availability of electric energy. When a large amount of energy is available, for example using photovoltaics during daytime, mode $\mathrm{A}$ is executed. When the energy supply is limited, for example with photovoltaics at night or on cloudy days, mode B is executed. Several SECAM reactors can run in parallel and be operated either in mode A or B to optimize the ammonia productivity according to the availability of renewable energy.

To facilitate the condensation of ammonia, the SECAM processes are operated at a pressure of $0.8 \mathrm{MPa}$. At this pressure, ammonia condenses at $20{ }^{\circ} \mathrm{C}$. $^{2}$ An additional benefit of the increased pressure is a positive effect on the reaction rate by the first order kinetics. ${ }^{11}$ The downside of the increased pressure is that it entails additional energy consumption and materials cost for making the reactor pressure resistant. Alternatively, the process can be run at atmospheric pressure if the produced ammonia is recovered by an extraction with water.

The energy needed for ammonia production and the share of operation modes A and B of SECAM processes with different Faradaic efficiencies at the two locations are presented in Table 1. The specifications of the process

Table 1. Comparison of the Performance of SECAM Implemented in Leuven, Belgium (Solar Energy $=158$ $\mathrm{kWh} / \mathrm{m}^{2} \cdot$ year) with an FE of 10,50 , and $85 \%$ and in the Atacama Desert, Chile $\left(353 \mathrm{kWh} / \mathrm{m}^{2} \cdot\right.$ year $)$ with an $\mathrm{FE}$ of 22.5, 50, and $85 \%^{a}$

$\begin{array}{clccr}\text { location } & \text { process } & \begin{array}{c}\text { energy consumption } \\ \left(\mathrm{MJ} / \mathrm{mol} \mathrm{NH}_{3}\right)\end{array} & \begin{array}{c}\text { mode A } \\ (\mathrm{h} / \text { day })\end{array} & \begin{array}{c}\text { mode B } \\ (\mathrm{h} / \text { day })\end{array} \\ \text { Leuven, } & \text { SECAM 10 } & 1.41 & 2.9 & 21.1 \\ \text { Belgium } & \text { SECAM 50 } & 0.64 & 2.9 & 2.0 \\ & \text { SECAM 85 } & 0.56 & 2.9 & 0.0 \\ \text { Atacama } & \text { SECAM 22.5 } & 0.87 & 6.4 & 17.6 \\ \text { desert, } & \text { SECAM 50 } & 0.64 & 6.4 & 4.4 \\ \text { Chile } & \text { SECAM 85 } & 0.56 & 6.4 & 0.0\end{array}$

${ }^{a}$ Average energy consumption and average daily operation time of modes $\mathrm{A}$ and $\mathrm{B}$ are reported.

parameters are given in the Supporting Information. The overpotentials used for the different half reactions are according to the state of the art. ${ }^{8,12-15}$

In Leuven, Belgium, a solar panel with an efficiency of $15 \%$ produces on average $430 \mathrm{Wh} / \mathrm{m}^{2} \cdot$ day $^{16}$ with a maximal power delivery of $150 \mathrm{~W} / \mathrm{m}^{2}$. This means mode A needs $150 \mathrm{~W}$ peak capacity (electrochemical reactor + compressor) for every square meter of solar panel. The produced solar electricity is sufficient to operate in mode A for $2.9 \mathrm{~h}$ /day on average. During these $2.9 \mathrm{~h}$, a reactor with a Faradaic efficiency of $10 \%$ produces enough $\mathrm{N}_{2} / \mathrm{H}_{2}$ gas mixture for mode $B$ to run for $21.1 \mathrm{~h}$. Together, this completes a day cycle of $24 \mathrm{~h}$. Therefore, the minimal required Faradaic efficiency is $10 \%$ in Belgium. The highest average solar irradiation is encountered in the Atacama desert in Chile. There, a solar panel with $15 \%$ efficiency produces $967 \mathrm{Wh} / \mathrm{m}^{2}$.day. ${ }^{17}$ This energy is sufficient for mode A to run $6.4 \mathrm{~h} /$ day on average. During these $6.4 \mathrm{~h}$, a reactor with a Faradaic efficiency of $22.5 \%$ produces enough $\mathrm{N}_{2} / \mathrm{H}_{2}$ gas mixture for mode $\mathrm{B}$ to run for $17.6 \mathrm{~h}$. Therefore, the minimal Faradaic efficiency needed in Chile is higher than in Belgium, viz. $22.5 \%$.

The energy consumption of SECAM ammonia synthesis is plotted against the Faradaic efficiency of the electrocatalysts in Figure 3. The energy consumption is highest at low Faradaic efficiency and drops rapidly when improving the Faradaic efficiency from $10 \%$ to $20 \%$. At Faradaic efficiencies above 


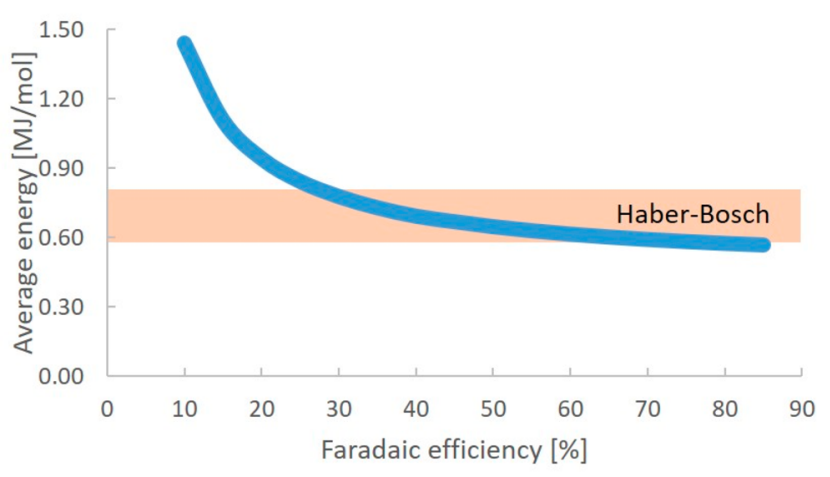

Figure 3. Average energy consumption of SECAM per mole of ammonia produced, against Faradaic efficiency of the electrocatalyst with an overpotential of $250 \mathrm{mV}$, compared to the energy consumption of the natural gas-based Haber-Bosch process. ${ }^{5,20,21}$

$20 \%$, the energy needs flatten. Enhancing the Faradaic efficiency from $30 \%$ to $85 \%$ causes a gain in energy of $37 \%$. Electrocatalyst development has been focused on enhancing Faradaic efficiency. The ARPA-E (Advanced Research Projects Agency-Energy) determined a minimal FE of $90 \%$ for the process to be economically feasible. ${ }^{18}$ However, with SECAM, ammonia synthesis could already be viable at Faradaic efficiencies of $20-30 \%$. Therefore, the main focus of future research should be on how to increase the current density, which on state-of-the-art electrodes is still far too low for commercial ammonia production and should be raised to at least 5-10 $\mathrm{mA} / \mathrm{cm}^{2}$.

Despite the high pressures and temperatures required for the Haber-Bosch process, it is surprisingly efficient at the very large scale at which it is operated. ${ }^{19}$ The traditional natural gasbased Haber-Bosch process is reported to have an energy consumption ranging from $0.58 \mathrm{MJ} / \mathrm{mol}$ to $0.81 \mathrm{MJ} / \mathrm{mol}$, depending on the source. ${ }^{5,20,21}$ SECAM is estimated to have similar energy requirements, ranging from $0.56 \mathrm{MJ} / \mathrm{mol}$ at $85 \%$ Faradaic efficiency to $0.92 \mathrm{MJ} / \mathrm{mol}$ at $20 \%$ Faradaic efficiency. As an additional advantage, SECAM allows for small-scale decentralized production, which is of interest to economically less developed parts of the world. ${ }^{22}$ With an efficient delocalized ammonia production at farms, transport costs for fertilizers can also almost be eliminated. ${ }^{23}$ The process discussed in this Viewpoint has limited $\mathrm{CO}_{2}$ footprint and can be operated with a fluctuating power source.

The SECAM process performs energy-efficient electrochemical ammonia production that is competitive with the Haber-Bosch process in terms of energy consumption. In contrast to the Haber-Bosch process, the discussed process is efficient at a small scale and allows a delocalized ammonia production. The process can be operated at a Faradaic efficiency as low as $20-30 \%$. Practical implementation of SECAM processes is awaiting the development of electrocatalysts with enhanced current density even at modest Faradaic efficiency.

Lander Hollevoet

Michiel De Ras

Maarten Roeffaers $\odot$ orcid.org/0000-0001-6582-6514

Johan Hofkens $\odot$ orcid.org/0000-0002-9101-0567

Johan A. Martens

\section{ASSOCIATED CONTENT}

Supporting Information

The Supporting Information is available free of charge at https://pubs.acs.org/doi/10.1021/acsenergylett.0c00455.

Detailed information on the executed calculations and assumptions made; a graphical representation of the process streams under varying operating conditions (PDF)

\section{AUTHOR INFORMATION}

Complete contact information is available at:

https://pubs.acs.org/10.1021/acsenergylett.0c00455

\section{Notes}

Views expressed in this Viewpoint are those of the authors and not necessarily the views of the ACS.

The authors declare no competing financial interest.

\section{ACKNOWLEDGMENTS}

We gratefully acknowledge the financial support of the Flemish Government through the Moonshot cSBO project P2C (HBC.2019.0108) and through long-term structural funding (Methusalem).

\section{REFERENCES}

(1) Licht, S.; et al. Ammonia synthesis by N2and steam electrolysis in molten hydroxide suspensions of nanoscale Fe2O3. Science (Washington, DC, U. S.) 2014, 345, 637-640.

(2) Zapp, K.-H.; et al. Ammonia, 1. Introduction. Ullmann's Encycl. Ind. Chem. 2012, 263-285.

(3) Emmett, P. H.; Brunauer, S. The Adsorption of Nitrogen by Iron Synthetic Ammonia Catalysts. J. Am. Chem. Soc. 1934, 56, 35-41.

(4) Kobayashi, Y.; Kitano, M.; Kawamura, S.; Yokoyama, T.; Hosono, H. Kinetic evidence: the rate-determining step for ammonia synthesis over electride-supported Ru. Catal. Sci. Technol. 2017, 7, $47-50$.

(5) Rafiqul, I.; Weber, C.; Lehmann, B.; Voss, A. Energy efficiency improvements in ammonia production - Perspectives and uncertainties. Energy 2005, 30, 2487-2504.

(6) Zhou, F.; et al. Electro-synthesis of ammonia from nitrogen at ambient temperature and pressure in ionic liquids. Energy Environ. Sci. 2017, 10, 2516-2520.

(7) Hao, Y. C.; et al. Promoting nitrogen electroreduction to ammonia with bismuth nanocrystals and potassium cations in water. Nat. Catal. 2019, 2, 2.

(8) Wang, M.; et al. Over $56.55 \%$ Faradaic efficiency of ambient ammonia synthesis enabled by positively shifting the reaction potential. Nat. Commun. 2019, 10, 341.

(9) McEnaney, J. M.; et al. Ammonia synthesis from N2 and $\mathrm{H} 2 \mathrm{O}$ using a lithium cycling electrification strategy at atmospheric pressure. Energy Environ. Sci. 2017, 10, 1621-1630.

(10) Garagounis; Vourros; Stoukides; Dasopoulos; Stoukides. Electrochemical Synthesis of Ammonia: Recent Efforts and Future Outlook. Membranes (Basel, Switz.) 2019, 9, 112.

(11) Zhang, S.; Zhao, Y.; Shi, R.; Waterhouse, G. I. N.; Zhang, T. Photocatalytic ammonia synthesis: Recent progress and future. EnergyChem. 2019, 1, 100013.

(12) $\mathrm{Li}, \mathrm{S}$. J. Amorphizing of Au Nanoparticles by CeOx-RGO Hybrid Support towards Highly Efficient Electrocatalyst for N2 Reduction under Ambient Conditions. Adv. Mater. 2017, 29, 1700001 .

(13) Zhang, B.; et al. Homogeneously dispersed multimetal oxygenevolving catalysts. Science (Washington, DC, U. S.) 2016, 352, 333337. 
(14) Zhao, S.; et al. Ultrathin metal-organic framework nanosheets for electrocatalytic oxygen evolution. Nat. Energy 2016, 1, 16184.

(15) Zhuang, Z.; et al. Nickel supported on nitrogen-doped carbon nanotubes as hydrogen oxidation reaction catalyst in alkaline electrolyte. Nat. Commun. 2016, 7, 10141.

(16) Súri, M.; Huld, T. A.; Dunlop, E. D.; Ossenbrink, H. A. Potential of solar electricity generation in the European Union member states and candidate countries. Sol. Energy 2007, 81, 12951305.

(17) Larraín, T.; Escobar, R.; Vergara, J. Performance model to assist solar thermal power plant siting in northern Chile based on backup fuel consumption. Renewable Energy 2010, 35, 1632-1643.

(18) ARPA-E. Renewable Energy to Fuels Through Utilization of Energy-Dense Liquids (REFUEL). https://arpa-e.energy.gov/sites/ default/files/documents/files/REFUEL_ProgramOverview.pdf (2016), 29-12-2019.

(19) Chen, J. G.; et al. Beyond fossil fuel-driven nitrogen transformations. Science (Washington, DC, U. S.) 2018, 360, eaar6611. (20) Renner, J. N.; Greenlee, L. F.; Herring, A. M.; Ayers, K. E. Electrochemical synthesis of ammonia: A low pressure, low temperature approach. Electrochem. Soc. Interface 2015, 24, 51-57.

(21) Giddey, S.; Badwal, S. P. S.; Kulkarni, A. Review of electrochemical ammonia production technologies and materials. Int. J. Hydrogen Energy 2013, 38, 14576-14594.

(22) Galloway, J. N.; Cowling, E. B. Reactive nitrogen and the world: 200 Years of change. Ambio 2002, 31, 64-71.

(23) Jewess, M.; Crabtree, R. H. Electrocatalytic nitrogen fixation for distributed fertilizer production? ACS Sustainable Chem. Eng. 2016, 4, 5855-5858. 